\title{
Retrospective analysis of 400 neuroendoscopic interventions: the Hungarian experience
}

\author{
Laszlo Bognar, M.D., Ph.D., Balazs Markia, M.D., and Laszlo Novak, M.D., Ph.D. \\ National Institute of Neurosurgery, Budapest, Hungary; and Department of Neurosurgery, \\ Health and Life Sciences Center, University of Debrecen, Hungary
}

\begin{abstract}
Object. The authors present the results of 400 consecutive neuroendoscopic interventions performed by a single surgeon in 373 patients during the last 8 years.

Methods. The study is based on a retrospective analysis of a continuously updated electronic database that includes patient history and radiological files. The success rate of the interventions is calculated.

Conclusions. The underlying pathological condition was hydrocephalus of various origins. The success rate within patient groups is given and the factors leading to successful surgery are emphasized. Recommendations on indications for neuroendoscopic operations are discussed.
\end{abstract}

KEY WORDS • endoscopy • hydrocephalus • intracranial cyst • children

The role of endoscopic procedures in pediatric and adult neurosurgery is rapidly growing. The indications for neuroendoscopy are increasing; they include not only the different forms of obstructive hydrocephalus, ${ }^{12}$ but also the treatment of communicating forms, for which the results are encouraging. ${ }^{9}$ The formerly accepted age limits no longer constitute exclusion criteria for an endoscopic procedure. ${ }^{18}$

In this paper we give a brief report of our experiences in endoscopic neurosurgery based on 400 consecutive operations performed by the senior author (L.B.) during the last 8 years.

\section{CLINICAL MATERIAL AND METHODS}

This study is based on a retrospective analysis. Patient data were collected in a continuously updated electronic database that contains digitally stored CT and MR images and relevant clinical data. The retrospective analysis included 373 patients (male/female ratio 179:194) and 400 procedures. The patients ranged in age from 11 days to 89 years. All 221 of the patients who were younger than 18 years of age were assigned to the pediatric group, and the remaining 152 patients were placed in the adult group (38\% were younger than 6 years of age [142 patients]). The mean follow-up period was 32 months (range 2 months- 8 years). We used endoscopy for treatment of hydrocephalus and cystic lesions of various origins, and also for tumor biopsy procedures when the lesion caused the obstruction of fluid

\footnotetext{
Abbreviations used in this paper: $\mathrm{CSF}=$ cerebrospinal fluid; $\mathrm{CT}=$ computerized tomography; ETV = endoscopic third ventriculostomy; MR = magnetic resonance; VP = ventriculoperitoneal.
}

pathways. Data were analyzed and the results (such as success rate and shunt substitution, failure, and complications) are discussed and conclusions reached regarding the effectiveness of different procedures in different diagnostic and age groups.

We defined the operation as a success if the patient did not require another intervention (repeated endoscopy, shunt insertion, or open surgery) as of the study date. Procedures were considered failures when symptoms did not improve and for some reason we did not perform another operation. If neuroimages demonstrated definitive regression and other causes could explain the symptoms, the operation was considered effective.

\section{RESULTS}

\section{Adult Patients}

Triventricular Hydrocephalus. As listed in Table 1, 112 ETVs, including eight tumor biopsy procedures, were performed for this indication. The patients with triventricular hydrocephalus were divided into three subgroups according to pathological features.

Aqueductal Stenosis. This cause was proven with cine phase-contrast MR imaging (76 operations). The success rate was $71 \%$. We performed only one repeated endoscopy. In 12 cases, the patients with aqueductal stenosis had previously undergone shunt insertions, in most cases with numerous repeated operations. Ten of these patients became shunt free after endoscopy.

Tectal or Pineal Tumor. Twenty-nine ETVs were performed, including eight biopsy procedures, in 28 patients with triventricular hydrocephalus caused by tumors. The 
L. Bognar, B. Markia, and L. Novak

biopsy procedure could only be safely performed when the tumor had a visible exophytic part in the ventricle. Of these eight cases, definitive histological findings could be verified in six; in two cases the size of the specimen was insufficient. Hydrocephalus was successfully treated in $70 \%$ of the patients, a success rate equal to that seen in the aqueductal stenosis group. One patient with repeated ETV was enrolled, and after that the individual became shunt free. We did not include patients who later underwent open surgery for tumor removal.

Other Pathological Conditions. There were four Chiari malformations and three complex developmental abnormalities in this group (seven operations). In five cases, endoscopy resolved the hydrocephalus.

Normal-Pressure Hydrocephalus. We treated 11 patients with normal-pressure hydrocephalus by using ETV. The clinical signs (gait disturbance, urinary incontinence, and dementia), CT findings, and iterative lumbar punctures were considered when establishing the diagnosis. Not only was the diagnosis difficult, but also the follow-up data were the poorest in this group because of patient noncompliance. In four cases the data were not sufficient for further analysis. In five others, clinical or radiological improvement was noticed. One patient later needed shunt insertion.

Isolated Ventricles. This group includes five mono- and two biventricular (both lateral ventricles) enlargements. None of the patients needed further treatment after endoscopic fenestration.

Intracranial Cysts. Twenty endoscopic surgeries (fenestrations) were performed to treat different types of intracranial cysts (four temporal, five suprasellar, five intraventricular, one frontal porencephalic, and five in the septum pellucidum). Six patients were lost to follow-up review. Of the remaining 14 patients, 12 improved both clinically and radiologically. In one patient the symptoms and follow-up MR images did not demonstrate changes, and the patient refused further treatment.

Colloid Cysts. We performed surgery on three colloid cysts. The lesion was removed totally in two cases. In all patients, symptoms improved, and hydrocephalus resolved postsurgery.

\section{Pediatric Patients}

As shown in Table 2, 247 endoscopic operations were performed in 221 patients.

Triventricular Hydrocephalus. The most common diagnosis was triventricular hydrocephalus (150 operations).

Aqueductal Stenosis. Triventricular hydrocephalus caused by proven aqueductal stenosis or with uncertain underlying pathological entities resulted in 108 operations. In many cases (especially in infants), we could not identify the precise underlying pathological condition because of the lack of preoperative MR or CT studies. In most of these cases, we first obtained a skull ultrasonography study, and in cases of obvious triventricular hydrocephalus in the absence of any complicating factor (signs of blood, mass lesion, cysts, or other coexisting lesions), we operated without CT or MR imaging studies, saving the child from unnecessary anesthesia. We include these cases in the first group, together with
TABLE 1

Results of neuroendoscopic procedures in adults

\begin{tabular}{lrrcc}
\hline \hline \multicolumn{1}{c}{ Diagnosis } & $\begin{array}{c}\text { No. of } \\
\text { Ops }\end{array}$ & $\begin{array}{c}\text { No of } \\
\text { Patients }\end{array}$ & $\begin{array}{c}\text { No. of } \\
\text { Repeated } \\
\text { Ops }\end{array}$ & $\begin{array}{c}\text { Success } \\
\text { Rate } \\
(\%)^{*}\end{array}$ \\
\hline triventricular hydrocephalus & 112 & 111 & 1 & 71 \\
$\quad$ aqueductal stenosis & 76 & 76 & 0 & 71 \\
w/ tumor & 29 & 28 & 1 & 70 \\
$\quad$ w/ other disorder & 7 & 7 & 0 & 71 \\
normal-pressure hydrocephalus & 11 & 11 & 0 & $45 \dagger$ \\
isolated ventricles & 7 & 7 & 0 & 100 \\
cysts & 20 & 20 & 0 & 90 \\
temporal & 4 & 4 & 0 & 100 \\
suprasellar & 5 & 5 & 0 & 80 \\
intraventricular & 5 & 5 & 0 & 100 \\
septum pellucidum & 5 & 5 & 0 & 80 \\
other & 1 & 1 & 0 & 100 \\
colloid & 3 & 3 & 0 & 100 \\
total & 153 & 152 & 1 & 73.5 \\
\hline
\end{tabular}

* Percentages reflect the success rate for all operations; this rate is not calculated based on the values in the other columns in the table.

$\dagger$ This rate is an approximation; patient compliance was poor and many were lost to follow up.

the cases of aqueductal stenosis. The group does not contain patients in whom later neuroimaging sessions verified specific pathological entities different from aqueductal stenosis. In this subgroup, the success rate was $63 \%$.

After dividing the patients into three age groups, a strong correlation was noticed between patient age and the operation's success rate. In patients younger than 6 months old, the success rate was only 34\%. In patients between 6 and 12 months of age, the success rate almost doubled to $63 \%$; in patients older than 1 year it reached $73 \%$ (Fig. 1). In 12 patients from the present study, a second ETV was performed because the first had failed. Interestingly, all of these patients improved after the second ETV and have not required shunt placement to the present day.

Tumor or Other Mass Lesion. Triventricular hydrocephalus caused by a tumor or other mass lesion resulted in 27 operations. Of the 26 patients with tumors causing CSF obstruction, two later required VP shunts, in one case repeated endoscopy was performed and eight patients underwent open surgery for tumor removal. In six cases, tumor biopsy procedures were performed simultaneously with ETV. In five of them, definitive histological findings could be obtained.

Other Pathological Conditions. Triventricular hydrocephalus with coexisting pathological entities was treated in 15 operations (four for Dandy-Walker malformations, two for Chiari malformations, two for spinal dysraphisms, and two others). Eleven ETVs were successful, and in three patients, VP shunts had to be inserted later. One patient was lost to follow-up review.

Posthemorrhagic and Postmeningitic Multicystic Hydrocephalus. We performed 35 endoscopic operations (fenestration, catheter placement) in 29 patients in this group. One endoscopic procedure (as the first surgery) resulted in a definitive cure in only $13.7 \%$ of patients. Of seven operations performed with endoscopically guided catheter positioning, five were definitive, and two patients needed further shunt revision. In most of the cases, we could achieve the appropriate one-shunt system with one ventri- 
TABLE 2

Results of neuroendoscopic procedures in children*

\begin{tabular}{|c|c|c|c|c|c|}
\hline Diagnosis & $\begin{array}{l}\text { No. of } \\
\text { Ops }\end{array}$ & $\begin{array}{l}\text { No. of } \\
\text { Patients }\end{array}$ & $\begin{array}{l}\text { No. of } \\
\text { Repeated } \\
\text { Ops }\end{array}$ & $\begin{array}{c}\text { Success } \\
\text { Rate }(\%) \dagger\end{array}$ & $\begin{array}{c}\text { Mean } \\
\text { Age } \\
(\text { mos })\end{array}$ \\
\hline $\begin{array}{l}\text { triventricular } \\
\text { hydrocephalus }\end{array}$ & 150 & 138 & 12 & 68.0 & 63 \\
\hline $\begin{array}{l}\text { aqueductal } \\
\text { stenosis (pre- } \\
\text { sumed) } \ddagger\end{array}$ & 108 & 97 & 11 & 63.0 & 59 \\
\hline w/ tumor & 27 & 26 & 1 & 84.0 & 84 \\
\hline w/ other disorder & 15 & 15 & 0 & 78.0 & 62.4 \\
\hline PHMHC & 35 & 29 & 6 & 13.7 & 13.1 \\
\hline PMHC & 13 & 11 & 2 & 38.0 & 44 \\
\hline isolated ventricles & 9 & 8 & 1 & 44.0 & 28 \\
\hline cysts & 40 & 35 & 5 & 66.0 & 69.8 \\
\hline suprasellar & 15 & 12 & 3 & 57.0 & \\
\hline intraventricular & 8 & 8 & 0 & 100.0 & \\
\hline quadrigeminal & 7 & 6 & 1 & 28.0 & \\
\hline septum pellucidum & 4 & 3 & 1 & 75.0 & \\
\hline other & 6 & 6 & 0 & 83.0 & \\
\hline total & 247 & 221 & 26 & 57.5 & 52.6 \\
\hline
\end{tabular}

* PHMHC $=$ posthemorrhagic postmeningitic multicystic hydrocephalus; $\mathrm{PMHC}=$ postmeningitic hydrocephalus.

$\dagger$ Percentages reflect the success rate for all operations; this rate is not calculated based on the values in the other columns in the table.

$\ddagger$ Ultrasonography findings were sufficient for diagnosis, and therefore neuroimaging with its accompanying radiation exposure and the necessity for induction of anesthesia were avoided.

cular catheter. In some cases the patient received two catheters, but we have no patient in whom we inserted three or more of the devices.

Postmeningitic Hydrocephalus. Eleven patients were treated with 13 operations (ETV, fenestration), three of them harbored multicystic lesions. The success rate is very poor in this group: only $38 \%$ of the patients improved permanently. The success rate rises to $66 \%$ if the three multicystic cases are excluded.

Intracranial Cysts. Thirty-five patients underwent 40 operations (fenestration, ETV) for intracranial cysts. The success rate in 15 suprasellar cysts was $57 \%$, in eight intraventricular cysts it was $100 \%$, in four septum pellucidum cysts it was $75 \%$, in seven quadrigeminal cysts it was $28 \%$, in one porencephalic cyst it was $100 \%$, and in five other cystic lesions it was $80 \%$.

Isolated Ventricles. Eight children with isolated ventricles were treated with fenestration. One of them required repeated endoscopy, and four underwent additional surgery for shunt placement.

\section{Postoperative Complications}

Of the 400 interventions, no surgery-related death was recorded (Table 3). Intraoperative bleeding occurred seven times (twice it was severe) and surgery was abandoned five times as a result. Two chronic subdural hematomas, one subcutaneous abscess, six subgaleal fluid collections, and one CSF leak occurred. The overall complication rate was $4.25 \%$; no patient suffered permanent disability or morbidity.

\section{DISCUSSION}

During the last 8 years we have performed 400 endo-

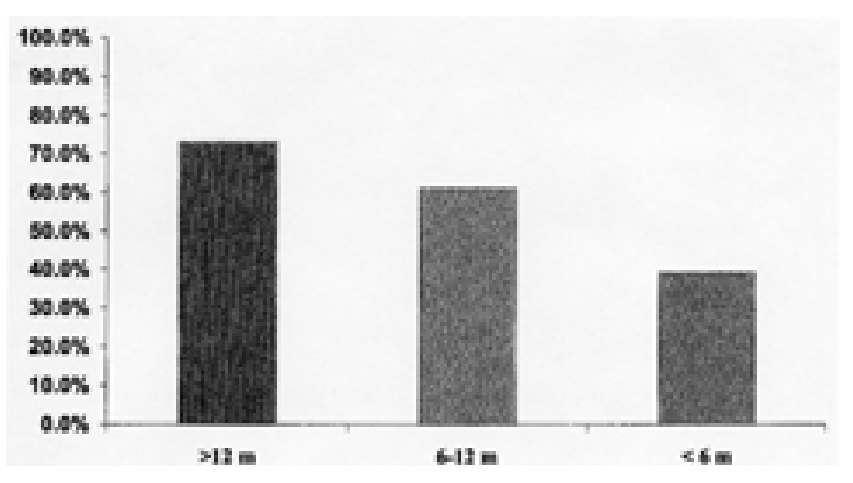

Fig. 1. Bar graph showing the success rate of ETV for treatment of triventricular hydrocephalus in children. $\mathrm{m}=$ months.

scopic interventions for several indications. As seen in our series, the majority of operations were ETVs performed to treat hydrocephalus. The overall success rate for treating adult hydrocephalus was $70 \%$, which is similar to that reported in earlier publications. $1,2,4,7,8,11,17,21$ We affirm that ETV is a safe and effective method of treating occlusive hydrocephalus of various origins. Although we had only 12 patients in whom initial treatment with CSF shunting had failed, we emphasize the fact that in 10 of these 12 cases, shunt revision and new shunt insertion were avoided with ETV. We plan to use repeated ETV in cases of shunt failure in patients with occlusive hydrocephalus in the future. . $^{14,18}$

The indications for ETV in normal-pressure hydrocephalus are subject to debate, but the decision to insert a shunt device is still controversial. In cases of intracranial cysts in adults, we recommend endoscopy as the most desirable technique. Our success rate for adults was $89 \%$, just as reported in larger series. ${ }^{3,6,13,20}$

The success rate for treating triventricular hydrocephalus in children was $63 \%$. The question of the timing of endoscopy and its effectiveness in younger patients is still a controversial topic. ${ }^{10,15,22}$ We found an obvious correlation between patient age and the success rate of ETV. In infants younger than 6 months, the success rate was only $34 \%$, but it doubled after the 1 st year (74\%). In cases of treatment failure in infants, the second operation was VP shunt placement. We also investigated the time elapsed between the endoscopic procedure and shunt insertion. We have found that $63 \%$ of the failures occur in the first 3 months (Fig. 2).

Since the era of perinatal intensive care units began, more and more often we have seen newborns with posthemorrhagic multicystic hydrocephalus. In most cases we try to postpone surgery as long as possible to increase the chance of success and reduce the risk of complications. Ventriculitis is a frequent preoperative problem and is most often caused by external drainage. Before the introduction of neuroendoscopy, thesepatients would frequently undergo several surgeries, and in the majority of cases two,three, or even more shunts or ventricular catheters would be placed in their heads. Nowadays, treatment of complex hydrocephalus is a rapidly developing field of neuroendoscopy. ${ }^{5,16}$ It has plenty of potential in terms of reducing hospital stay, number of procedures, and inplant expenses.

In multicystic hydrocephalus, the most difficult part of the treatment is the proper positioning of the ventricular catheter to drain as much of the cyst fluid as possible. The 
L. Bognar, B. Markia, and L. Novak

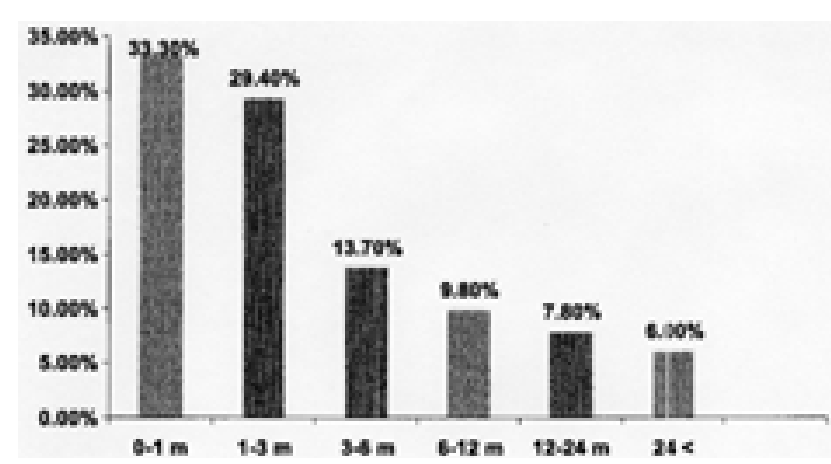

Fig. 2. Bar graph showing the elapsed time between ETV and shunt insertion in cases of treatment failure in children.

use of endoscopy helps by providing the opportunity to open cysts into each other, and allowing the positioning of the ventricular catheter under visual control. With these techniques, the number of shunt placement procedures can be minimized, but currently CSF shunting is still the definitive treatment for this condition. Endoscopic operations performed as the first surgery were definitive treatments in only $13.7 \%$ of patients. After endoscopic catheter placement, shunt revision was necessary in only two of the seven cases. Based on these data, we strongly recommend the adoption of this technique.

Our results with intracranial cysts are also similar to those of earlier studies, although noticeably with suprasellar cysts we achieved only a 58\% success rate, although it is much higher in the literature. ${ }^{13,19}$

Since 1997, with the introduction of neuroendoscopy into everyday neurosurgical practice, we have accumulated a large series, making possible the analysis of our own experiences. We were able to learn to use the technique safely, as the low morbidity and absent mortality rates show. In those groups in which the case numbers were higher (triventricular hydrocephalus), the effectiveness of the procedure is similar to other experienced authors' findings. In the last few years, ETV has become the first choice for treatment of occlusive hydrocephalus and intracranial arachnoid cysts in our department, as it is in many leading neurosurgical centers.

In analyzing our data, we noticed that ETV is an open possibility for patients who previously received shunts for triventricular hydrocephalus and who were just experiencing a shunt failure. In these cases, endoscopy may be the best choice instead of shunt revision in patients with large ventricles and proven aqueductal stenosis or occlusion. The question of the role of endoscopy in the treatment of normal-pressure hydrocephalus is still being debated. Our series does not contain enough data to draw any conclusions on this topic. More cases and further analysis are required.

The effectiveness of ETV increases with age. In patients younger than 6 months of age, the success rate is only $34 \%$, but after 12 months it rises to $73 \%$, which is as good as in adults. We conclude that ETV is the right choice in patients older than 6 months, whereas in those younger than this age the shunt/ETV question should be decided according to ventricle size, underlying pathological condition, age, weight, and gestational anamnesis.
TABLE 3

Complications occurring during 400 operations

\begin{tabular}{lc}
\hline \multicolumn{1}{c}{ Complication } & No. (\%) \\
\hline death & $0(0.00)$ \\
intraop bleeding & $7(1.75)$ \\
chronic subdural hematoma & $2(0.50)$ \\
wound infection & $1(0.25)$ \\
subgaleal collection & $6(1.50)$ \\
CSF leakage & $1(0.25)$ \\
total & $17(4.25)$ \\
\hline
\end{tabular}

\section{CONCLUSIONS}

We have found that endoscopy is a very useful tool in simplifying complex, multicystic hydrocephalus. Future trends should aim in this direction. The success rate of this modality in arachnoid cyst treatment was $66 \%$, but interestingly, with suprasellar cysts it was only $57 \%$. This is much lower than in other authors' series, and the fact that our rates were worse than theirs will motivate us to keep trying to match their rates.

\section{References}

1. Beems T, Grotenhuis JA: Long-term complications and definition of failure of neuroendoscopic procedures. Childs Nerv Syst 20:868-877, 2004

2. Brockmeyer D, Abtin K, Carey L, et al: Endoscopic third ventriculostomy: an outcome analysis. Pediatr Neurosurg 28: 236-240, 1998

3. Caemaert J, Abdullah J, Calliauw L, et al: Endoscopic treatment of suprasellar arachnoid cysts. Acta Neurochir (Wien) 119: 68-73, 1992

4. Cinalli G, Sainte-Rose C, Chumas P, et al: Failure of third ventriculostomy in the treatment of aqueductal stenosis in children. J Neurosurg 90:448-454, 1999

5. Cipri S, Gambardella G: Neuroendoscopic approach to complex hydrocephalus. Personal experience and preliminary report. J Neurosurg Sci 45:92-96, 2001

6. Decq P, Brugieres P, Le Guerinel C, et al: Percutaneous endoscopic treatment of suprasellar arachnoid cysts: ventriculocystostomy or ventriculocystocisternostomy? Technical note. J Neurosurg 84:696-701, 1996

7. Feng H, Huang G, Liao X, et al: Endoscopic third ventriculostomy in the management of obstructive hydrocephalus: an outcome analysis. J Neurosurg 100:626-633, 2004

8. Gangemi M, Donati P, Maiuri F, et al: Endoscopic third ventriculostomy for hydrocephalus. Minim Invasive Neurosurg 42:128-132, 1999

9. Gangemi M, Maiuri F, Buonamassa S, et al: Endoscopic third ventriculostomy in idiopathic normal pressure hydrocephalus. Neurosurgery 55:129-134, 2004

10. Gorayeb RP, Cavalheiro S, Zymberg ST: Endoscopic third ventriculostomy in children younger than 1 year of age. J Neurosurg 100 (5 Suppl Pediatrics):427-429, 2004

11. Grunert P, Charalampaki P, Hopf N, et al: The role of third ventriculostomy in the management of obstructive hydrocephalus. Minim Invasive Neurosurg 46:16-21, 2003

12. Hellwig D, Grotenhuis JA, Tirakotai W, et al: Endoscopic third ventriculostomy for obstructive hydrocephalus. Neurosurg Rev 28:1-38, 2005

13. Kirollos RW, Javadpour M, May P, et al: Endoscopic treatment of suprasellar and third ventricle-related arachnoid cysts. Childs Nerv Syst 17:713-718, 2001

14. Koch D, Grunert P, Filippi R, et al: Re-ventriculostomy for 


\section{Retrospective analysis of 400 neuroendoscopic interventions}

treatment of obstructive hydrocephalus in cases of stoma dysfunction. Minim Invasive Neurosurg 45:158-163, 2002

15. Koch D, Wagner W: Endoscopic third ventriculostomy in infants of less than 1 year of age: which factors influence the outcome? Childs Nerv Syst 20:405-411, 2004

16. Oi S, Abbott R: Loculated ventricles and isolated compartments in hydrocephalus: their pathophysiology and the efficacy of neuroendoscopic surgery. Neurosurg Clin N Am 15:77-87, 2004

17. Scarrow AM, Levy EI, Pascucci L, et al: Outcome analysis of endoscopic III ventriculostomy. Childs Nerv Syst 16:442-445, 2000

18. Siomin V, Cinalli G, Grotenhuis A, et al: Endoscopic third ventriculostomy in patients with cerebrospinal fluid infection and/or hemorrhage. J Neurosurg 97:519-524, 2002

19. Sood S, Schuhmann MU, Cakan N, et al: Endoscopic fenestration and coagulation shrinkage of suprasellar arachnoid cysts. Technical note. J Neurosurg 102 (1 Suppl):127-133, 2005
20. Tirakotai W, Schulte DM, Bauer BL, et al: Neuroendoscopic surgery of intracranial cysts in adults. Childs Nerv Syst 20: 842-851, 2004

21. Tisell M, Almstrom O, Stephensen H, et al: How effective is endoscopic third ventriculostomy in treating adult hydrocephalus caused by primary aqueductal stenosis? Neurosurgery 46: 104-111, 2000

22. Wagner W, Koch D: Mechanisms of failure after endoscopic third ventriculostomy in young infants. J Neurosurg 103 (1 Suppl):43-49, 2005

Manuscript received October 17, 2005.

Accepted in final form November 21, 2005.

Address reprint requests to: Laszlo Bognar, M.D., Ph.D., Department of Neurosurgery, Health and Life Sciences Center, University of Debrecen, Nagyerdei krt. 98, 4012 Debrecen, Hungary. email: bognarl@jaguar.dote.hu. 